
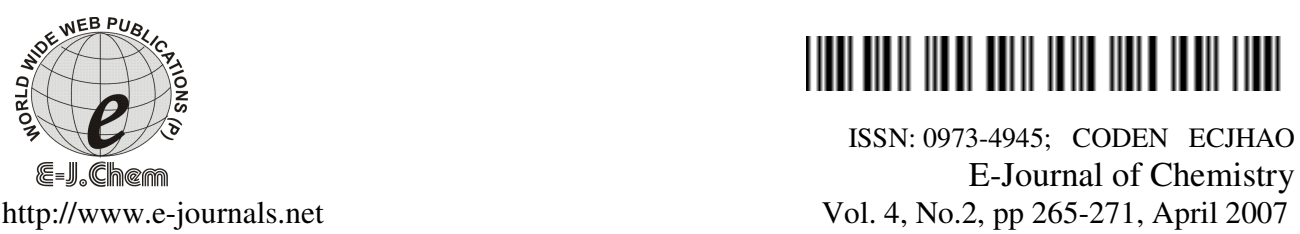

\title{
Synthesis, Characterization and Copolymerization of N-(phenylamino)maleimide with MMA
}

\author{
B. L. HIRAN*, S. N. PALIWAL, \\ JYOTI CHOUDHARY and P. R. CHOUDHARY \\ Chemical Kinetics and Polymer Research Laboratory, \\ Department of Chemistry, \\ M. L. S. University, Udaipur (Raj.) India.313 001. \\ E-mail-hiranbl@rediffmail.com
}

Received 23 November 2006; Accepted 22 December 2006

\begin{abstract}
The free radical copolymerization of $\mathrm{N}$-(phenylamino)maleimide $(\mathrm{N}-$ PAMI) was carried. The copolymerization with methyl methacrylate (MMA) was performed at $65^{\circ} \mathrm{C}$ with AIBN as the initiator in THF solvent. Resulting copolymer was characterized by density measurement, intrinsic viscosity, solubility, FT-IR \& ${ }^{1} \mathrm{H}$ NMR spectroscopy. Effect of the solvent and time on copolymer yield was also investigated. The molecular weight of copolymer was determined by gel permeation chromatography (GPC). The thermal stability of copolymer was determined by Thermogravimetric analysis (TGA).
\end{abstract}

Keywords: N-(phenylamino)maleimide, free radical copolymerization, characterization

\section{Introduction}

Condensation type polyimides have certain disadvantages, like insolubility and infusibility ${ }^{1,2}$ and hence are difficult to process. To overcome these processing disadvantages polymaleimide have synthesized by employing the addition polymerization technique in solution. Most aromatic polyimides produced by the thermal solid-state phase imidization show insolubility and infusibility, which make processing difficult and limit applications. Addition type polyimides were developed mainly to overcome processing disadvantage ${ }^{3-7}$. Aromatic polyimides have been noted for excellent characteristics such as thermo oxidative stabilities and electrical properties as well as chemical resistance. The polymers have been 
widely used for number of applications ${ }^{8-11}$. N-substituted maleimides are known to copolymerized free radically ${ }^{12-18}$.

In order to investigated the possibility of obtaining better polymers from $\mathrm{N}$-substituted maleimide. We have tried to prepare some new better polymer. In this paper we report the synthesis and characterization of copolymer of $\mathrm{N}$-(phenylamino)maleimide with MMA (C-PAMI) using AIBN as a free radical initiator.

\section{Experimental}

\section{Materials}

Phenyl hydrazine was distilled and maleic anhydride was recrystallized from acetone. Methyl methacrylate (MMA) $(\mathrm{CDH})$ were shaken two to three times with $5 \% \mathrm{NaOH}$ to eliminate hydroquinone inhibitor, dried over anhydrous $\mathrm{CaCl}_{2}$ for $8 \mathrm{~h}$ and distilled. The head and tail fractions were discarded. AIBN (2,2'-azobis-isobutironitrile (spectorchem.) was recrystallized twice from methanol prior to use. BPO (benzoyl peroxide) (CDH) were used as received. THF was purified by distillation after being refluxed for $2 \mathrm{~h}$ in the presence of sodium. DMF and methanol used in the present work were of analytical grade and were used as received.

\section{Measurements}

${ }^{1} \mathrm{H}-\mathrm{NMR}$ spectra of monomer and polymer samples were taken in $\mathrm{CDCl}_{3}$ on a Bruker DPX200/DPX-300 spectrometer at 200/300 MHz. The internal reference used was TMS. FT-IR spectra of the monomer and polymer samples were recorded on a shimadzu $8201 \mathrm{pc}$ (4000$400 \mathrm{~cm}^{-1}$ ) FT-IR spectrometer, using $\mathrm{KBr}$ pellet technique. The viscosities measurements were carried out in DMF at $30 \pm 2^{\circ} \mathrm{C}$, using on Ubbelohde suspended level viscometer. Elemental analysis was made on Carlo-Erba Model NA 500 series analyzer. The thermograms in air were obtained on a Mettler TA-3000 system, at a heating rate of $10^{\circ} \mathrm{C} / \mathrm{min}$.

\section{Preparation of $\mathrm{N}$-(phenylamino)maleimide (N-PAMI)}

$\mathrm{N}$-(phenylamino)maleimide was synthesized in two steps from maleic anhydride and phenyl hydrazine. (described below and shown in scheme-1)

\section{$N$-(phenylamino)maleiamic acid (N-PAMA)}

Phenyl hydrazine (10.8 gm, 0.1mole) in $30 \mathrm{~mL}$ DMF was gradually added to well stirred $\mathrm{DMF} /$ maleic anhydride $(9.8 \mathrm{gm}, 0.1 \mathrm{~mole})$ in flat bottom flask and then stirred for $3 \mathrm{~h}$ at room temperature. This solution is poured in crushed ice water. The yellow colored solid $(\mathrm{N}$ PAMA) is precipitated. This precipitate was filtered and dried at $70^{\circ} \mathrm{C}$. It was recrystallized from methanol solvent to obtain pure N-PAMA in $75 \%$ yield, m.p. $220^{\circ} \mathrm{C}$. The IR spectrum showed absorptions at 3527 (carboxylic acid O-H), 1560 (amide $\mathrm{N}-\mathrm{H}), 3410,3069$ (aromatic and alkene $\mathrm{C}-\mathrm{H}$ ), 1708 (carboxylic acid and amide), 1278 (carboxylic acid $\mathrm{C}-\mathrm{O}), 1618(\mathrm{C}=\mathrm{C}$ aromatic, $911(\mathrm{CH}=\mathrm{CH}) \mathrm{cm}^{-1} .{ }^{1} \mathrm{H}-\mathrm{NMR}\left(300 \mathrm{MHz}, \mathrm{TMS}, \mathrm{CDCl}_{3}, \delta \mathrm{ppm}\right): 7.5-6.8(2 \mathrm{~d}, \mathrm{j}=7.5$ $\mathrm{Hz}$ in phenyl), $6.16(\mathrm{~s}, 2 \mathrm{H}, \mathrm{CO}-\mathrm{CH}=\mathrm{CH}-\mathrm{CO}), 3.27(\mathrm{~s}, 1 \mathrm{H}$ in $\mathrm{N}-\mathrm{H}), 3.74(\mathrm{~N}-\mathrm{H}$ singlet $)$, $11.40(\mathrm{~s}, 1 \mathrm{H}, \mathrm{COOH})$.

\section{$N$-(Phenylamino)maleimide (N-PAMI)}

Cyclodehydration was carried by treating N-PAMA with conc. $\mathrm{H}_{2} \mathrm{SO}_{4}$ and $\mathrm{P}_{2} \mathrm{O}_{5}$ carried out to maleimide. In flat bottom flask containing DMF solution of N-PAMA (20.6 gm, 0.1 mole) in $30 \mathrm{~mL}$ DMF, to this DMF (30mL) solution of $\mathrm{P}_{2} \mathrm{O}_{5}(7.4 \mathrm{gm})$ \& conc. $\mathrm{H}_{2} \mathrm{SO}_{4}(1 \mathrm{~mL})$ was added gradually with stirring. This solution was stirred for $2 \mathrm{~h}$ at $70^{\circ} \mathrm{C}$. The reaction 
mixture was cooled and poured into crushed ice water to obtain the yellow color precipitate of N-PAMI. The precipitate was filtered and washed several times with water and finally dried. N-PAMI was recrystallized from methanol solvent. The yield was $72 \%$ and melting point $215^{\circ} \mathrm{C}$. The IR spectrum showed absorption frequencies 3062.2 (aromatic and alkene C-H stretch), 3433 (-NH stretch), 1778.4 and 1716.7 (symmetric and asymmetric stretch of $\mathrm{C}=\mathrm{O}$ in a five member imide ring $), 1596.8,1517.0$ and $1495.8(\mathrm{C}=\mathrm{C}$ aromatic $), 1416.2(\mathrm{C}-\mathrm{N}$ stretch) $\mathrm{cm}^{-1} .{ }^{1} \mathrm{H}$ NMR $\left(300 \mathrm{M} \mathrm{Hz}, \mathrm{TMS}, \mathrm{CDCl}_{3}, \delta \mathrm{ppm}\right):$ 7.5-6.8 (2d, 4H phenyl) 3.74 (s, $1 \mathrm{H}, \mathrm{N}-\mathrm{H}), 6.3$ and 7.1 (s, 2H, O=C-CH=CH-C=O).

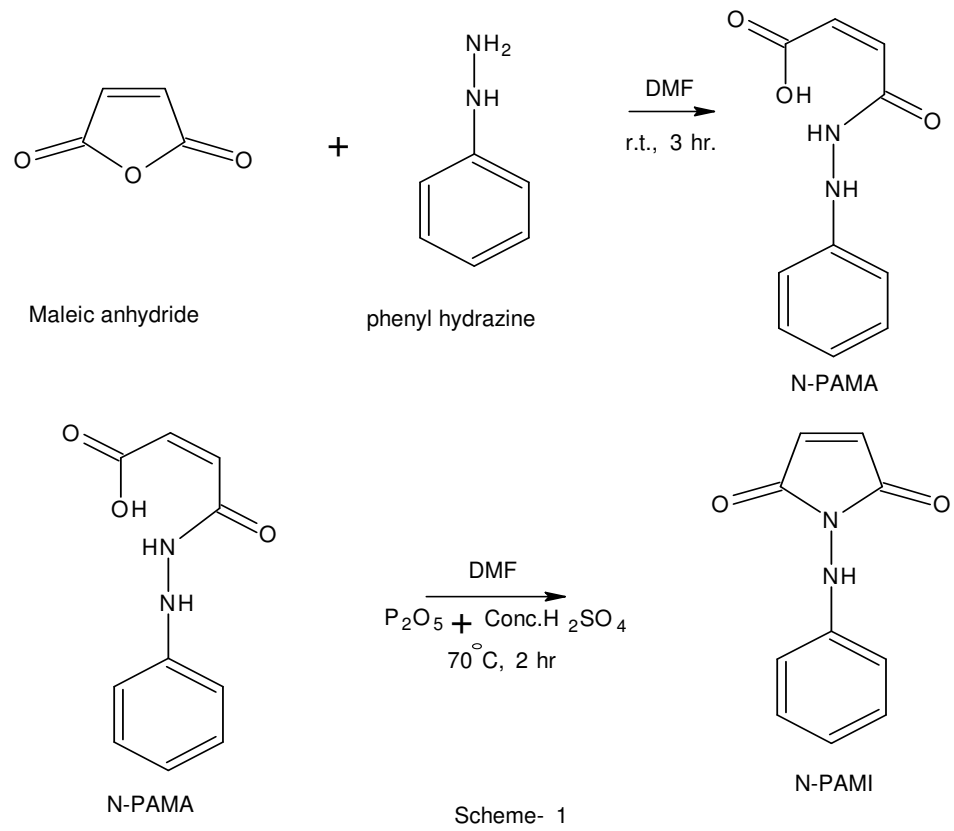

\section{Polymerization Procedures}

Calculated amount of monomer N-PAMI with MMA in 70mL THF solvent were taken in a round bottom flask. Then 20mg AIBN was added to the reaction mixture as a free radical initiator. The copolymerization reaction was carried out at $65^{\circ} \mathrm{C}$ for $24 \mathrm{~h}$. Polymer samples were isolated in water containing $20 \%$ methanol. The copolymer were purified by first dissolving in THF and then, reprecipitating in excess quantity of methanol-water mixture. The precipitated copolymer were washed several times and dried at $60^{\circ} \mathrm{C}$ under vaccum.<smiles>O=C1C=CC(=O)N1Nc1ccccc1</smiles>

N-PAMI<smiles>COC(=O)C(C)C</smiles>

MMA

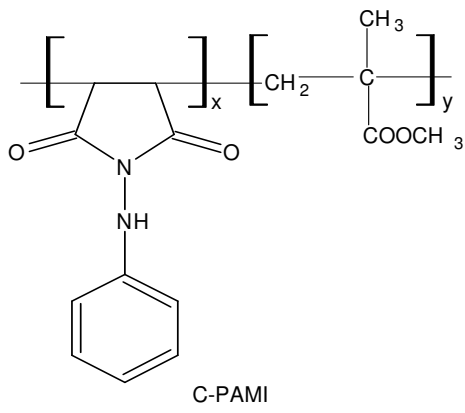


Table 1. Radical copolymerization of N-PAMI and MMA in THF at $65^{\circ} \mathrm{C}$

\begin{tabular}{lccccc}
\hline Polymer code & $\begin{array}{c}\text { Feedmole fraction } \\
\text { of N-PAMI }\end{array}$ & $\begin{array}{c}\text { Polymerization } \\
\text { time }(\mathrm{h})\end{array}$ & $\begin{array}{c}\text { Yield } \\
(\%)\end{array}$ & $\begin{array}{c}\mathrm{N} \\
(\%)\end{array}$ & Appearance \\
\hline C-PAMI & 0.5 & 24 & 37.07 & 4.57 & Light yellow \\
\hline
\end{tabular}

\section{Results and Discussion}

\section{Solvent - Initiator System}

Free radical copolymerization of maleimides is known to be useful on the synthesis of polymaleimides. This method was applied to their preparation from N-PAMI and vinyl monomers to find suitable condition in which to prepare copolymaleimide with relatively high yield. The effect of initiator \& solvent were investigated in details. The effect of reaction solvents and initiator on yield of C-PAMI was formed in different pairs of solvent initiator is summarized in Table 2.

Table 2. Radical copolymerization of N-PAMI and MMA in various solvent-initiators

\begin{tabular}{lcc} 
system & & \\
\hline Solvent & AIBN & BPO \\
\hline & Yield of C-PAMI(\%) & Yield of C-PAMI (\%) \\
\hline THF & 37.07 & 36.01 \\
DMF & 22.34 & 21.30 \\
Ethylacetate & 26.94 & 28.20 \\
$p$-Dioxane & 29.43 & 30.40 \\
Acetone & 31.20 & 30.10 \\
\hline
\end{tabular}

The percentage yield of the C-PAMI in the AIBN -DMF system was poor compared to AIBN- dioxane and BPO- dioxane. AIBN-Acetone system gave better yield of C-PAMI over the AIBN-EA \& BPO-EA system. AIBN -THF system of copolymerization gave better yield then other solvent-initiator system including BPO-THF system. Examination of all the aspect AIBN-THF system was most suitable for the present copolymerization process.

\section{Effect of Time on polymer yield}

The effect of reaction solvents and time of stirring on yield of C-PAMI is summarized in Table 3. Table 3 revel that N-PAMI gave better yield of copolymerization in $24 \mathrm{~h}$ in THF solvent.

Table 3. Radical copolymerization of N-PAMI and MMA in different time.

\begin{tabular}{llllr}
\hline Solvent & & \multicolumn{2}{c}{ C-PAMI } & \multicolumn{2}{c}{ Yield (\%) } \\
\hline \multirow{3}{*}{ THF } & $12 \mathrm{~h}$ & $24 \mathrm{~h}$ & $36 \mathrm{~h}$ & $48 \mathrm{~h}$ \\
\cline { 2 - 5 } & 12.01 & 37.90 & 39.07 & 40.01 \\
\hline
\end{tabular}

\section{Solubility}

Table 4 summarizes the relative solubilities of copolymer samples in number of polar and non-polar solvents at $30^{\circ} \mathrm{C}$. The investigated copolymer samples are soluble in Acetone, Cyclohexanone, THF, DMF, Dichloromethane, DMSO, and solvent and insoluble in $\mathrm{CCl}_{4}$, Xylene, Hexane Ethanol, Methanol and Water. Solubility behaviour in the later solvents depends in the solvent taken. 
Table 4. Solubility behaviour of monomer, homopolymer and copolymer in polar and non-polar solvents at $30^{\circ} \mathrm{C}$.

\begin{tabular}{ccc}
\hline Solvent & N-PAMI & C-PAMI \\
\hline Acetone & S & S \\
Cyclohexanone & S & S \\
$p$-Dioxane & IS & S \\
THF & $\mathrm{S}$ & $\mathrm{S}$ \\
DMF & $\mathrm{S}$ & $\mathrm{S}$ \\
Dichloromethane & $\mathrm{S}$ & $\mathrm{S}$ \\
DMSO & $\mathrm{S}$ & $\mathrm{S}$ \\
Chloroform $_{\text {CCl }_{4}}$ & $\mathrm{~S}$ & $\mathrm{~S}$ \\
Xylene $_{\text {Toluene }}$ & $\mathrm{IS}$ & $\mathrm{S}$ \\
Hexane & $\mathrm{IS}$ & $\mathrm{IS}$ \\
Methanol & IS & PS \\
Water & PS & IS \\
\hline
\end{tabular}

S- Soluble, PS-Partially soluble, IS-Insoluble

\section{Intrinsic Viscosity [ $\eta]$}

Intrinsic viscosity $[\eta]$ is a measure of hydrodynamic volume and depends on molecular weight as well as on the size of the polymer coil in a given solution. The value of average $\eta$ in DMF solution at $30^{\circ} \mathrm{C}$ is listed in Table 5. The value of $\eta$ is $0.240 \mathrm{dL} / \mathrm{gm}$ for C-PAMI. The value of $\eta$ depends on the composition of N-PAMI.

Table 5. The Intrinsic viscosity, density and molecular weight of C-PAMI.

\begin{tabular}{llcc}
\hline Polymer & $\begin{array}{l}\text { Density } \\
\rho\left(\mathrm{g} / \mathrm{cm}^{3}\right)\end{array}$ & $\begin{array}{c}\eta \\
(\mathrm{dL} / \mathrm{g})\end{array}$ & $\mathrm{M}_{\mathrm{w}}$ \\
\hline C-PAMI & 0.8491 & 0.240 & 25581.4 \\
\hline
\end{tabular}

\section{Molecular weight}

Molecular weight of C-PAMI is determined by GPC method using THF solvent. The number average molecular weight of C-PAMI is 900.1. The weight average molecular weight of C-PAMI is 1730.1.The average molecular weight of C-PAMI is 25581.4.

\section{Density}

The densities of solid copolymer samples were determined at $30^{\circ} \mathrm{C}$ by displacement method with single stem pycnometer ${ }^{19}$ using water as a non-solvent. The density of C-PAMI is given in Table 4. The density of C-PAMI is $0.8491 \mathrm{~g} / \mathrm{cm}^{3}$. The result indicates that density of CPAMI is less then water.

\section{Spectral characterization}

In this study ${ }^{1} \mathrm{H}-\mathrm{NMR}$ and FT-IR spectroscopy were used to characterize the copolymer. In the FT-IR spectrum, the major characteristic absorption bands are observed at $3319 \mathrm{~cm}^{-1}$ (-NH stretch), 1780.3, and $1724.2 \mathrm{~cm}^{-1}$ (C=O symmetric and asymmetric stretch in a five member imide ring and $\mathrm{C}=\mathrm{O}$ stretch of ester), 1602.7, and $1496.9 \mathrm{~cm}^{-1}$ (aromatic, $\mathrm{C}=\mathrm{C}$ and amide group). The imide group is also confirmed from the bands observed at 1495.8(Ar-N stretch), 1416.2(C-N stretch), 1164(C-N-C), 1170 and $760 \mathrm{~cm}^{-1}$. The broad medium intense 
band at $1596.8 \mathrm{~cm}^{-1}$, strong intense band at $1571.0 \mathrm{~cm}^{-1}$ and a medium band at $1495.8 \mathrm{~cm}^{-1}$ correspond to the aromatic $(\mathrm{C}=\mathrm{C})$ band. The broad stretching bands at $3433.6 \mathrm{~cm}^{-1}$ represent secondary amine $(-\mathrm{NH})$. These characteristic bands confirm that units of both the monomers N-PAMI and MMA are present in the copolymer samples. Compared with the IR spectra of monomers, it was found that the characteristic peaks of the double bond disappeared in the spectrum of the copolymer, for example, $911 \mathrm{~cm}^{-1}$ for N-PAMI.

The ${ }^{1} \mathrm{H}-\mathrm{NMR}$ spectra of the copolymer showed the following chemical shifts. The $\delta$ at 7.27$6.91 \mathrm{ppm}$ is $5 \mathrm{H}$ of aromatic phenyl ring. A $\delta$ at $4-5-5.0 \mathrm{ppm}$ appeared for $2 \mathrm{H}$ of $\quad-(\mathrm{CH}-\mathrm{CH})-$ in the polymer main chain and $\delta$ observed at $3.4-4.6$ ppm corresponds to overlapping of $1 \mathrm{H}$ in $\mathrm{N}-\mathrm{H}$ group of amino phenyl maleimide segment and $3 \mathrm{H}\left(-\mathrm{OCH}_{3}\right)$ of MMA segment. The $\delta$ in the range $0.8-1.4 \mathrm{ppm}$ is of $2 \mathrm{H}$ of methyl group while at $1.43-2.20 \mathrm{ppm}$ for $2 \mathrm{H}$ of methylene group. ${ }^{1} \mathrm{H}-\mathrm{NMR}$ spectrum also confirmed the consumption of all the vinyl groups of the comonomers because absorptions of vinyl groups of both monomers are absent in the spectrum, for example, $6.8 \mathrm{ppm}$ for vinyl protons of N-PAMI and 5.0-6.0 pm for MMA. This indicated that the polymerization happened via the opening of the double bond.

\section{Thermal Properties}

It is well known that polymaleimide is potential heat and chemical resistant material so maleimide is widely used as a monomer for modified polymeric systems. Only single step degradation at temperature of over $300{ }^{\circ} \mathrm{C}$ was observed for polymaleimide in TGA. The thermograms were obtained by heating copolymer sample in air at $10^{\circ} \mathrm{C} / \mathrm{min}$. The typical TGA curve was obtained of C-PAMI. The results of percentage weight loss suffered from $100^{\circ} \mathrm{C}$ to $600^{\circ} \mathrm{C}$ at 100 Intervals are furnished in Table 7 .

The initial decomposition temperature $\mathrm{T} i$, temperature for maximum weight loss Tmax, and final decomposition temperature $\mathrm{T} f$ of first degradation step of are given in Table 6 . The copolymer C-PAMI is decomposing through a one step procedure. As the copolymer sample content of N-PAMI is $50 \%$ the initial decomposition temperature $(\mathrm{T} i)$ is $220^{\circ} \mathrm{C}$ and weight loss for the first step became larger. The first step weight loss was range to 60 to $75 \%$. The weight loss of C-PAMI upto $600^{\circ} \mathrm{C}$ is $89-90 \%$. Table 7 revels that weight loss was below 0.8 to $8 \%$ up to $300^{\circ} \mathrm{C}$ in copolymer sample

Table 6. Thermal Behaviour of copolymer

\begin{tabular}{llllc}
\hline Polymer & $\mathrm{T} i\left({ }^{\circ} \mathrm{C}\right)$ & $\operatorname{Tmax}\left({ }^{\circ} \mathrm{C}\right)$ & $\mathrm{T} f\left({ }^{\circ} \mathrm{C}\right)$ & Residue at $500^{\circ} \mathrm{C}$ \\
\hline C-PAMI & 220 & 300 & 330 & $11 \%$ \\
& 330 & 400 & 550 & \\
\hline
\end{tabular}

Table 7. Percentage weight loss of copolymer at various temperatures from the TGA.

\begin{tabular}{cccccc}
\hline Polymer & $200^{\circ} \mathrm{C}$ & $300^{\circ} \mathrm{C}$ & $400^{\circ} \mathrm{C}$ & $500^{\circ} \mathrm{C}$ & $600^{\circ} \mathrm{C}$ \\
\cline { 2 - 6 } & \multicolumn{5}{c}{ Weight loss, $\%$} \\
\hline C-PAMI & 2 & 49 & 84 & 89 & 90 \\
\hline
\end{tabular}

\section{Conclusions}

Synthesis, through free radical copolymerization of N-PAMI with MMA has been investigated. The most suitable initiator-solvent pair for the copolymerization was found to 
be AIBN-THF. The investigated copolymaleimide show excellent solubility in THF, DMF, DMSO, chloroform, dichloromethane, Acetone and Cyclohexanone. The characterization of copolymer was carried out through intrinsic viscosity, molecular weight distribution, elemental analysis, FT-IR and ${ }^{1} \mathrm{H}-\mathrm{NMR}$ spectral analysis. Copolymer show good thermal stability and it degrade in two-steps.

\section{Acknowledgements}

We are thankful to CDRI Lucknow and SICART Vallabh-Vidhyanager for analysis work. One of the authors, S. N. Paliwal is thankful to UGC, New Delhi for financial assistance.

\section{References}

1. Hergenrother P M, Polym. Prepr, 1984, 25, 977.

2. Mittal K L, (eds.) Polyimides: Synthesis, Characterization and Applications, Plenum press New York 1984, 1\&2.

3. Coleman J L E and Conrady J J A, J. Polym. Sci., 1959, 38, 241.

4. Tawney P O and Snyder R H and Conger R P and Leibbrand K A and Stiteler C H and Williams A R, J. org. Chem., 1961, 26,15.

5. Cubbon R C P, polymer, 1965, 6, 419.

6. Barrales-Rienda J, Gonzalez D L, Camp, J L and Gonzalez R, J. Macromol. Sci. Chem., 1997, A11, 267-286.

7. Kagawa K, Oishi T, Matsusaki K and Fujimoto M, Polymer, 1995, 36, 941-948.

8. Feger C J, Khojasteh M M and McGrath J E, Polyimides: Materials, Chemistry and Characterization; Feger, C J and Khojasteh, M M and McGrath, J E (eds.) Elsevier Science Publishers: Amsterdam. 1989.

9. Lupinski J H and Moore R S, Polymeric Materials for Electronics Packaging and Interconnection; Lupinski J H and Moore, R S (eds.) ACS Symposium Series 407, American Chemical Society: Washington, 1989.

10. Wilson D, Stenzenberger H D and Hergenrother P M, Polyimide; Blackie: Glasgow, Chapt. 1990,

11. Scroog C E and Polyimides, J. Polym. Sci. (Macromol Rev.), 1976, 11 (1), 161-208.

12. Lin Z, Shi L and Hung J, J. Macromol. Sci., Pure \& Appl Chem., 2000, A 37, 219- 238

13. Xulin J, Ping X, Wamli L and Deyue Y, J. Polym. Sci. Part A: Polym. Chem., 2000, 38, 1203-1209.

14. Schalti I E, Baskan D A and Ygci Y, Polym. Bull, 2000, 44, 261-268.

15. Samyna C, Ballet W, Verbiest T, Van B M and Persoons A, Polymer, 2001, 42, 8511-8516.

16. Chunqing L, Huaming L and Pengsheng L, J. Macromol. Sci. Part A-Pure and Applied Chemistry, 2004, A41, 1161-1172.

17. Oswal S L, Sarkar N S, Bhandari V K, Oza H B and Patel C B, Iranian Polymer Journal, 2004, 13(4), 297-305.

18. Oswal S L, Patel C B and Malek N I, J. Macromol. Sci. Part A-Pure and Applied Chemistry, 2006, 43, 289-303.

19. Weissberger, A Physical methods of Organic Chemistry, Interscience, New York, 1985,1 Ch 4.

20. Oishi T, Polym J, 1981, 13, 65 .

21. Oishi T and Fujimoto M J, Polym. Sci. Part A Polym. Chem. 1992, 30, 821. 


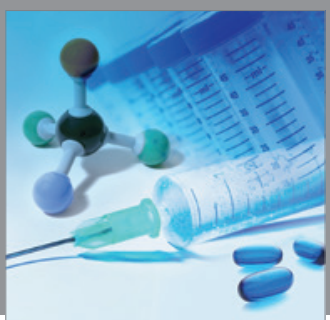

International Journal of

Medicinal Chemistry

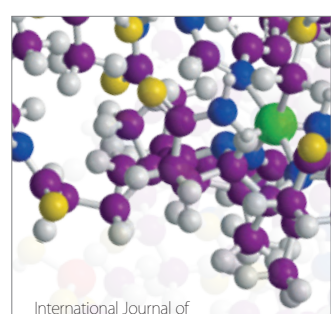

Carbohydrate Chemistry

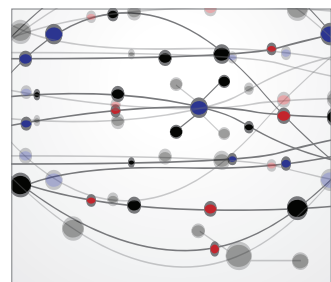

The Scientific World Journal
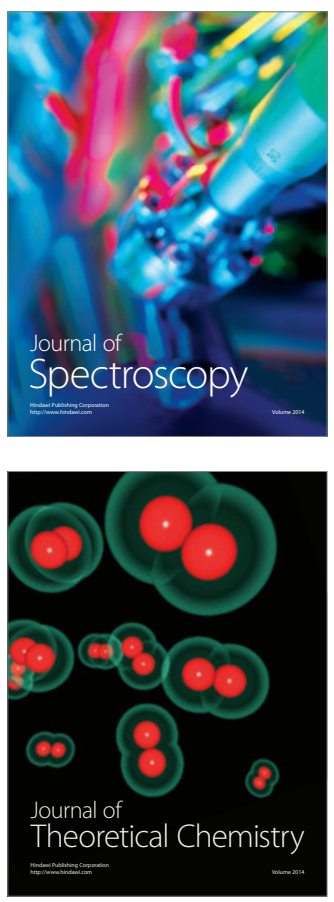
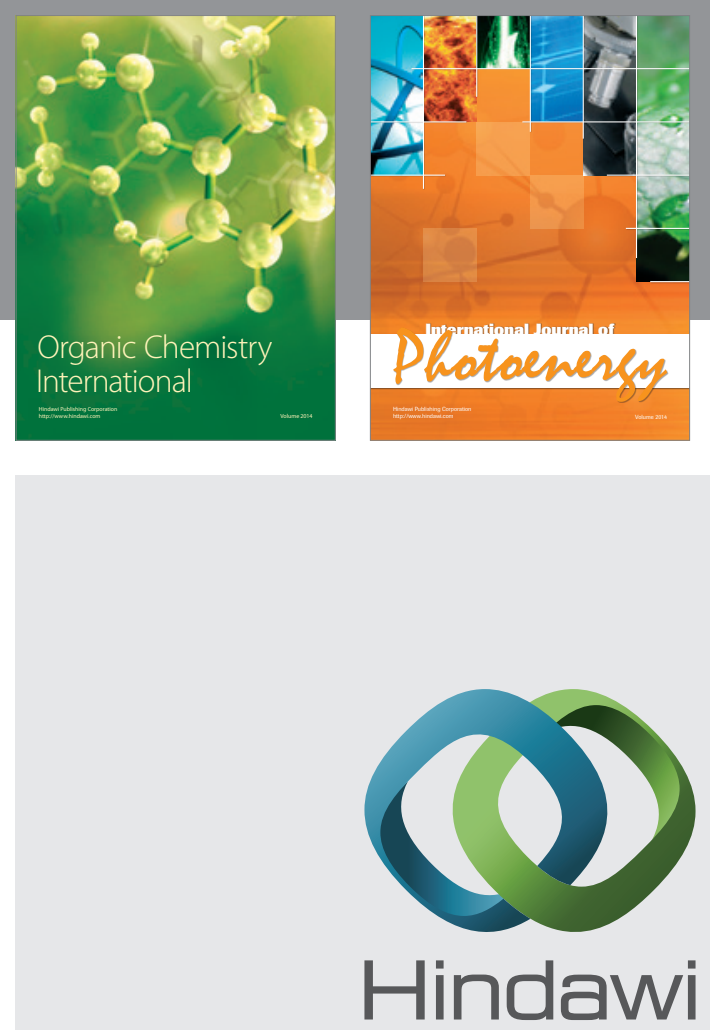

Submit your manuscripts at

http://www.hindawi.com
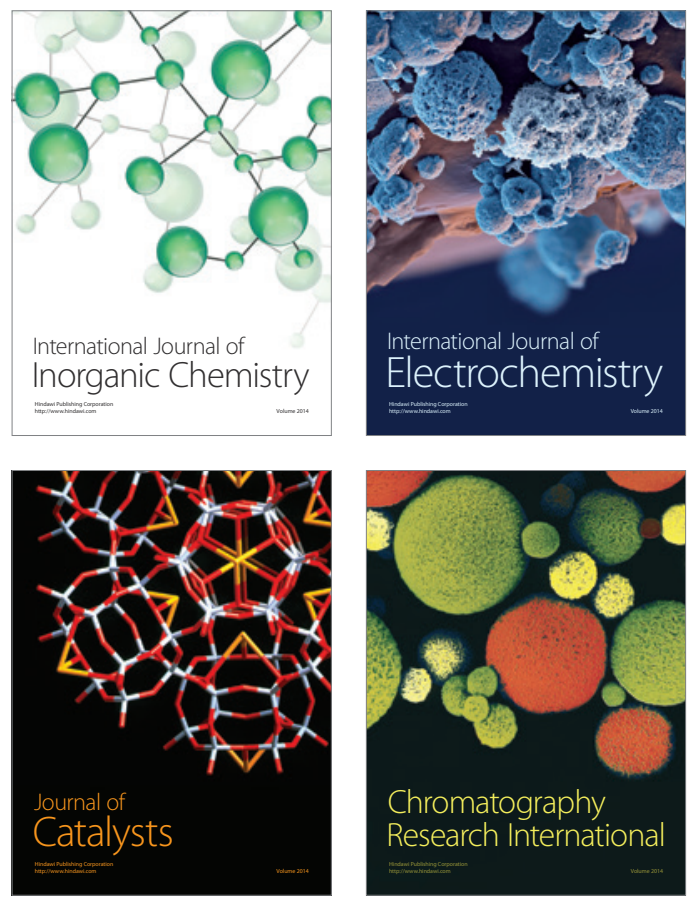
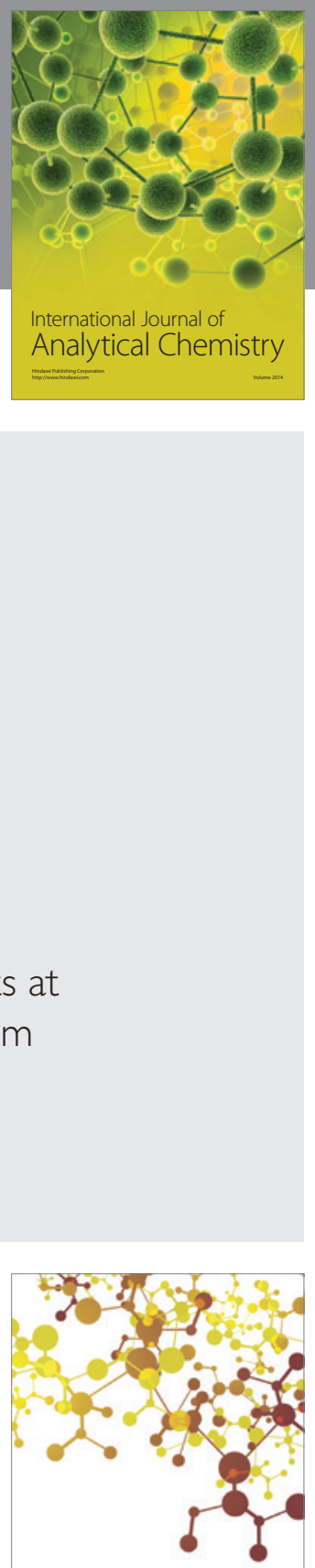

Journal of

Applied Chemistry
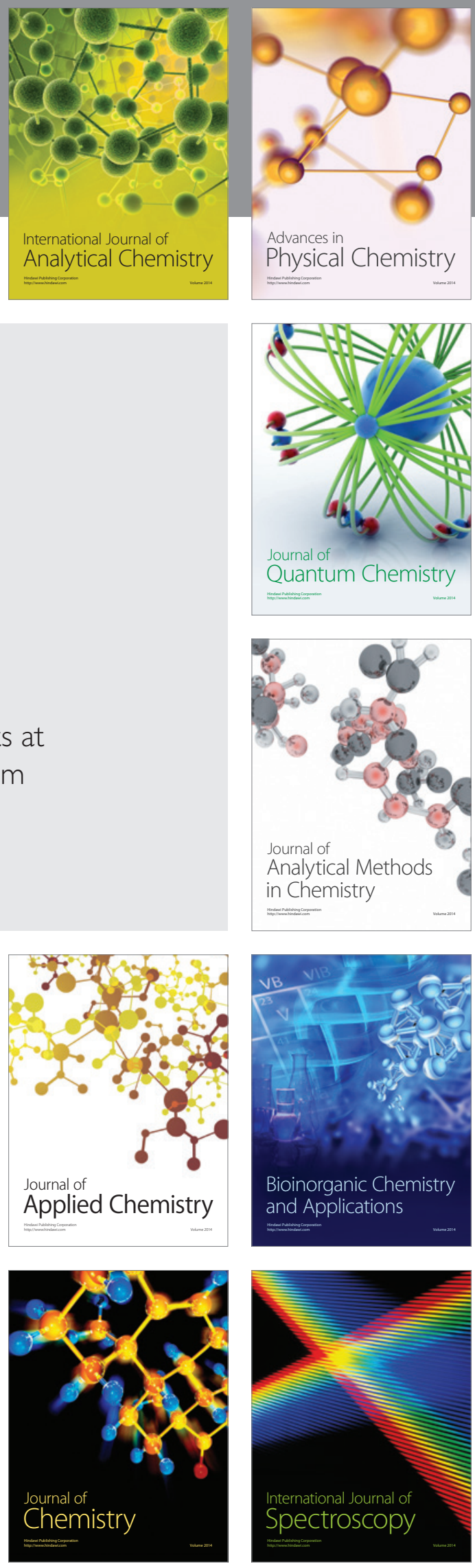